Preface

\title{
Express Polymer Letters is renewing
}

\author{
Tamás Bárány* ${ }^{*}$, László Mészáros ${ }^{(\mathbb{1}}$ \\ Department of Polymer Engineering, Faculty of Mechanical Engineering, Budapest University of Technology and \\ Economics, Müegyetem rkp. 3., H-1111 Budapest, Hungary
}

\section{Dear Readers,}

Express Polymer Letters has been published by the Department of Polymer Engineering at the Budapest University of Technology and Economics (BME) for 15 years. Under the guidance and dedicated work of Prof. J. Karger-Kocsis and Prof. T. Czigány, it quickly developed into a prestigious journal and still holds its position as one of the leading journals in its field (JCR IF(2020) 4.161; Q1 in 'Polymer Science'). Since then, the world has changed a lot, both in science and computing, and Prof. Karger-Kocsis is no longer with us. In the last 15 years, the focus of polymer science research has also changed dramatically: e.g. the rise of graphene, functional and smart polymers, biopolymers like polylactic acid, and recycling and environmental issues. Readers' needs have also changed. A significant proportion of articles are being read on smartphones and tablets rather than at a computer desk or in a library.

All these changes constitute a significant challenge for a journal. We want to respond effectively to them, so the journal is being renewed in many ways. Prof. T. Czigány asked Dr. T. Bárány to take on the role of Editor-in-Chief and Dr. L. Mészáros to take on the role of Deputy Editor-in-Chief so that he can responsibly serve as Rector of the 240-year-old BME. Both of us have been doing a lot of background work in the Editorial Board since the launch of the journal. Over the years, the number of manuscripts submitted to the journal has steadily increased, therefore we have changed the structure of the Editorial Board. We have divided the disciplines covered by the journal into several sections, each of which is assigned a topic editor, an active researcher in the field, who oversees the fate of each submitted manuscript from

\footnotetext{
${ }^{*}$ Corresponding author, e-mail: barany.tamas@gpk.bme.hu (C) BME-PT
}

submission to decision. The topic editors and their topics are the following: Dr. A. Toldy - 'Polymer chemistry' and 'Thermoset polymers, coatings'; Dr. T. Tábi - 'Biopolymers'; Dr. T. Bárány 'Elastomers' and 'Thermoplastic composites'; Dr. K. Molnár - 'Fibrous materials' and 'Smart polymers'; Dr. L. Mészáros - 'Functional polymers' and 'Thermoplastics, blends'; Dr. G. Szebényi - 'Medical polymers' and 'Thermoset composites'; Dr. F. Ronkay - 'Polymer foams' and 'Recycling of polymers'.

The renewal also comprises changes in the International Advisory Board. Researchers who have been carrying out high-quality work for a long time will be joined by other researchers and they together will provide high-level expertise in the whole field covered by the journal.

Of course, as you see, the website is also renewed both in terms of appearance and content. The main guiding principle for these changes has been to make it easier to use and display on different devices.

What has not changed is free-of-charge publication, free access, and a quick decision-making process (the average time from the submission to the acceptance of a publication is $8-9$ weeks). The authors and reviewers are primarily responsible for the high quality of the articles published in the journal. We thank them for their work and count on them in the future.

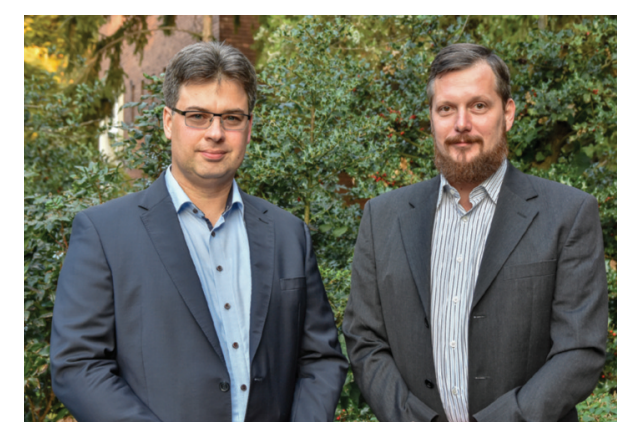

Dr. Tamás Bárány and Dr. László Mészáros 